\title{
Descentralização do Fundeb e federalismo da política educacional: uma análise à luz do conceito de accountability
}

\section{Decentralization of Fundeb andfederalism of educational policy: an analysis with reference to the concept of accountability}

\author{
Descentralizaión de el Fundb y el federalismo de la política \\ educativa: un análisis a partir del concepto de accountability
}

\author{
Ana Carla Bliacheriene ${ }^{1}$ \\ Elisa Vanzella de Lucena² \\ Marcus Vinicius de Azevedo Braga $^{3}$ \\ Temistocles Murilo de Oliveira Junior ${ }^{4}$
}

\section{Resumo:}

Revisa a literatura sobre accountabilitye constrói, a partir desta, um modelo para análise dos atores do Fundo de Manutenção e Desenvolvimento da Educação Básica e de Valorização dos Profissionais da Educação Fundeb, no contexto do federalismo brasileiro e da execução descentralizada das políticas públicas educacionais. Conclui pela fragilidade da estrutura de accountability, com a relação desigual entre o controle mútuo dos atores, pela possibilidade de lacunas e conflitos e aponta a necessidade de fortalecimento da dimensão vertical, de coordenação da dimensão horizontal e de sinergia entre essas dimensões.

Palavras-Chave:Accountability; Fundeb; Política de Educação.

\section{Abstract:}

This article reviews the literature aboutaccountability and builds from this, a model for analysis of the actors of the Brazilian Fund for the Development of Basic Education-Fundeb, in the context of Brazilian federalism and decentralized implementation of educational public policies. The paper concludes showing the weakness of accountability structure with the unequal relationship between the mutual control of actors, the possibility of gaps and conflicts, and points out the need to strengthen the vertical dimension, coordinating the horizontal and synergy between these dimensions.

Key Words: Accountability; Fundeb; Education Policy.

1 Professora dos cursos de pós-graduação em Gestão das Organizações de Saúde da FMRP-USP, Gestão de Políticas Públicas EACH-USP e Direito da FDRP-USP. Professora da graduação da FDRP-USP. Livre-docente em Direito Financeiro pela FD-USP. Mestre e doutora em Direito Social, sub-área Direito das Relações Econômicas Internacionais pela PUC-SP.http://lattes.cnpq.br/7188513922196059

2 Mestranda no Programa de Pós-Graduação em Direito da Faculdade de Direito de Ribeirão Preto (FDRP - USP). http://lattes.cnpq.br/7355508812084622 3 Doutorando em Políticas Públicas (UFRJ) e Analista de Finanças e Controle da CGU. http://lattes.cnpq.br/6009407664228031

4 Doutorando em Políticas Públicas (UFRJ) e Analista de Finanças e Controle da CGU. http://lattes.cnpq.br/6001057558977088 


\section{Resumen:}

El artículo revista a literatura sobre el accountability y edifica, a partir de aquí, un modelo para la evaluación de los resultados del Fondo de Manutención y Desarrollo de la Educación Básica-Fundeb, en el contexto del federalismo brasileño y de la ejecución descentralizada de las políticas públicas educativas. El trabajo concluyó pela fragilidade de la estructura de accountability, con una relación de desigualdad entre el control mutuo de los ámbitos, por la posibilidad de las lacunas y conflictos y la apuesta a la necesidad de fortalecimiento de la dimensión vertical, la coordinación de la dimensión horizontal y la sinergia entre las dimensiones.

Palavras-Chave: Responsabilidad; Fundeb; Política de Educación.

\section{Introdução}

O presente artigo se propõe, realizar uma análise crítica do sistema de accountability da gestãomunicipal do Fundo de Manutenção e Desenvolvimento da Educação Básica e de Valorização dos Profissionais da Educação - Fundeb, identificando fragilidades e possibilidades à luz do referido conceito.

O "pano de fundo" da discussão posta é a fragilidade do federalismo brasileiro e do financiamento das políticas públicas descentralizadas, no que tange à accountability, adotando como modelo de análise um caso controverso, o Fundeb. Escolheu-se este por se tratar de um fundo interfederativo e que além de grande capilaridade e materialidade, traduz os dilemas de governança de políticas descentralizadas em um país de dimensões continentais, com municípios autônomos, que engendra programas de coordenação interfederativa cuja dimensão de implementação se sobrepõe claramente à dimensão de controle.

O modelo de financiamento do Fundeb é um aperfeiçoamento do Fundo de Manutenção e Desenvolvimento do Ensino Fundamental e de Valorização do Magistério (Fundef), instituído pela Emenda Constitucional n. ${ }^{\circ}$ 14, de setembro de 1996, e regulamentado pela Lei n. ${ }^{\circ}$ 9.424, de 24 de dezembro daquele mesmo ano, chegando ao Fundeb como um paradigma de repartição amadurecida de recursos na federação, na luta pela distribuição mais equânime de recursos para a redução das desigualdades regionais e que envolve por ano, com base em dados do Fundo Nacional de Desenvolvimento da Educação (FNDE/MEC) de 2013, aproximadamente R\$ 111 bilhões (cerca de USD 48 bilhões), o equivalente ao Produto Interno Bruto do Uruguai nesse mesmo exercício.

Após uma revisão de literatura sobre accountability, o artigo proporá uma tipologia de análise a luz desse conceito e se debruçará, então, na discussão do federalismo e das políticas educacionais, chegando ao Fundeb, exemplo a ser analisado, na interação desses atores e nas possibilidades e limitações no conceito citado.

\section{Accountability, revisão de literatura e tipologia}

Accountability, a palavra ainda não traduzida para o português, e que raramente figura nos periódicos populares do Brasil, tem grande relevância no debate político moderno, em especial na questão da construção da democracia, na garantia de direitos fundamentais e ainda, no combate da corrupção, do abuso do poder e da ineficiência da gestão pública, marcas de um país que ainda engatinha nos valores democráticos e que traz grandes heranças patrimonialistas.

Segundo Pessanha (2007, p. 141), a accountability:

(...) implica manter indivíduos e instituições responsáveis pelo seu desempenho, ou seja, alguns atores tem o direito, por vezes o dever, de controlar o desempenho de outros atores, segundo um conjunto de padrões pré-estabelecidos.

O que permite aplicar sanções corretivas e atribuir responsabilidades, contexto essencial para que os governos, com suas estruturas cada vez mais complexas, com múltiplos atores e partes interessadas, possam ter mitigada a sua captura por interesses diferentes da coletividade. 
Ceneviva (2006), por sua vez, apresenta a accountability como o controle e a fiscalização dos agentes públicos e destaca que alguns estudiosos do tema indicam que apenas mecanismos de controle formais e institucionalizados compõe esse conceito, enquanto outras pesquisas agregam atores como a imprensa e a sociedade civil, denominando de accountabilityqualquer atividade de controle, fiscalização e monitoramento, entendimento este que adotaremos neste artigo. Classificações a parte, a accountability se detém a ideia de se controlar o poder estatal, limitando-o, como pilar de uma sociedade democrática.

O'Donnell (1998) no estudo das chamadas Poliarquias (DAHL, 1997), define duas dimensões da accountability, uma horizontal (1998, p. 40), que se caracteriza pela "(...) existência de agências estatais que tem o direito e o poder legal e que estão, de fato, dispostas e capacitadas para realizar ações que vão desde a supervisão de rotina a sanções legais (...)" e uma outra dimensão, vertical, entendida como "(...) ações realizadas individualmente, ou por algum tipo de ação organizada e/ou coletiva, com referência aqueles que ocupam posições em instituições do Estado, eleitos ou não" (1998, p. 28), uma visão de dimensões complementares e que se fortalecem pela sua sinergia, equilibrando a ação burocrática de agências e a interação popular.

No que tange a interação popular, esta se caracteriza pelos mecanismos eleitorais e pelo chamado controle social, defendendo o autor a importância de uma atuação em rede dessas agências, demonstrando ele também a preocupação, no caso da América Latina, e seus novos regimes democráticos, com a fragilidade da accountability horizontal nesse caso (O'DONNELL, 2003), com uma atuação apenas reativa e intermitente, focadas não no equilíbrio entre os poderes, e sim para dar conta do fenômeno da corrupção.

Mainwaring (2003), autor que se propõe a acrescentar conceitos a partir das discussões de O'Donnell, apresenta questões relacionadas a um excesso de mecanismos de accountability, que podem gerar entraves na implementação de políticas que atendem aos anseios do cidadão, preocupação ratificada por recentes documentos da OCDE no trato da transparência no Brasil (OECD, 2011), apontando como efeitos colaterais da transparência os atrasos na tomada de decisões, além da captura de informações por grupos de interesses, ou ainda, o aumento potencial de conflitos, indicando essa discussão os limites da accountability cotejados a sua relevância por Mainwaring, em especial no caso da América Latina, com uma abordagem na questão da corrupção já destacada por O’Donnell.

Nos seus estudos, Mainwaring (2003) defende também a necessidade de se existir o poder sancionatório ínsito ao conceito de accountability, pois para ele esse conceito se materializa apenas quando uma agência pública ou oficial é formalmente questionável por outro ator, em uma rede de supervisão, o que não se dá necessariamente em uma relação biunívoca de principal-agente, de delegação, mas pela existência de agências, a similitude dos chamados órgãos de controle, que tenham poder de supervisão.

Na crítica do modelo horizontal-vertical de O'Donnell (1998), Mainwaring (2003) aponta que a dimensão vertical passa uma ideia de hierarquia, de assimetria de poder, fora do aparelho estatal (Estado $\times$ Sociedade) e que a dimensão horizontal se traduz pela independência das agências. Entretanto, o autor defende que algumas relações intraestatais são verticais, com características de delegação, criticando o modelo anterior.

Estabelece este então um paradigma de accountability dividida em uma dimensão intraestatal, formada por relações de principal-agente, do sistema legal e de agências de supervisão e de uma outra dimensão, chamada de eleitoral, que busca superar as ideias de hierarquia e de independência do paradigma anterior.

Esses autores destacam a existência de dimensões vinculadas aos tipos de atores e à sua atuação, e que estas dimensões se fortalecem quando interagem, sendo necessário para a boa accountability o robustecimento não só da participação popular, mas também pela existência de instituições técnicas e empoderadas, no contexto do equilíbrio entre os poderes, como elementos para o controle do poder estatal, no combate à usurpação e à corrupção.

Já Schedler (1999) define a accountability pela presença de três elementos: a transparência das decisões/ ações; a justificação explícita desses atos; e a existência de sanções no caso de desvio em relação aos 
acordos pré-estabelecidos. Nesse sentido, ele desmembra a accountability como a composição de dois outros conceitos, a answerability e o enforcement, caracterizados pela exposição motivada e pela capacidade de forçar o cumprimento do estabelecido, respectivamente.

Koppell (2010), por sua vez foca a sua análise das instituições por ele chamadas de "accountable", ou seja, responsáveis, caracterizando-se estas pela sua transparência, pela possibilidade de serem punidas por baixo desempenho e por estarem sujeitas a avaliação, apresentando a accountability como uma fonte de credibilidade e de sustentação do poder, exaltando a questão da legitimidade das instituições em um contexto democrático.

A transparência é definida, por Koppell (2010), como uma visão de disponibilização motivada das ações da instituição, constituindo esta pré-requisito essencial para a accountability. Ele aponta outras quatro categorias que caracterizam a instituição "accountable", como a liability, na possibilidade de sofrer sanções positivas e negativas; a controllability, na possibilidade da instituição ser supervisionada; na responsability, como fidelidade a princípios e leis; e a responsiveness, como preocupação na produção de resultados.

Desses autores, focados em instituições, tem-se que a accountability se caracteriza pela transparência motivada de ações e decisões, com uma estrutura que possibilite sanções, aderência as normas e ainda, que exista uma cultura voltada a obtenção de resultados, de atendimento as demandas estatuídas.

Tem-se então os modelos de Koppell e Schedler, focados nas instituições e suas características, enquanto os modelos de O'Donnell e Mainwaring são vinculados aos agentes de promoção da accountability e a sua rede de atuação, dimensões que se interelacionam, em uma linha radial, de uma rede de agência, complementado por um nível atomizado, da estrutura e sua organização interior, voltada para a ser "accountable". Essas dimensões podem ser arranjadas em uma tipologia de análise da accountability, como proposto a seguir:

Quadro 1: Tipologia de análise da accountability

\begin{tabular}{|c|c|}
\hline \multirow{2}{*}{ Foco } & Quesito a ser analisado \\
\hline \multirow{2}{*}{$\begin{array}{c}\text { Instituição que executa a } \\
\text { política } \\
\text { (Dimensão interna) }\end{array}$} & ACCOUNTABLE-Estrutura da instituição que favoreça a conformidade e o atingimento de resultados \\
\cline { 2 - 2 } $\begin{array}{c}\text { TRARÊNCIA-Disponibilização de informações e a sua devida motivação } \\
\text { Sistema de }\end{array}$ & DISCIPLINAMENTO-Estrutura da instituição que possibilite a ela ser avaliada de forma corrente e \\
sancionada positiva e negativamente
\end{tabular}

Fonte: Construção do autor Braga

A tipologia proposta combina dois olhares, um externo e um interno, na construção da accountability a partir de uma visão de rede, de mais autonomia e de uma visão interna, da própria organização, convergindo essas duas linhas de ação como complementares e conduzidas por diferentes atores.

A partir dessa tipologia, analisaremos a gestão municipal do Fundeb no desenho atual, apontando as fragilidades e possibilidades desta no que tange a accountability. Entretanto, faz-se necessário adensar o conhecimento da estrutura de financiamento da educação básica no federalismo brasileiro. 


\section{Federalismo, Fundeb e os seus atores principais}

\section{Considerações sobre o federalismo no Brasil}

Em contraposição à centralização do governo militar, a chamada Constituição cidadã reavivou a ideia da municipalização das políticas públicas, em mais uma das sístoles e diástoles da política educacional, motivada pela influência de organismos internacionais, para o desenvolvimento de comunidades (BRAGA, 2015), impulsionado o governo central pelo desejo de desoneração frente à crise, concentrando recursos no âmbito federal e descentralizando a execução na esfera subnacional, reforçando a ideia de que o problema da educação não é a falta de recursos e sim os desarranjos de gestão (FELIX ROSAR, 2008), que podem ser solucionados pelo fortalecimento do poder local e pelo incremento da participação, ainda que sujeita ao risco de captura pelas oligarquias locais (COHEN, FRANCO; 2007).

Essa discussão dos benefícios, malefícios e ainda, das motivações dos processos de descentralização é controversa e se prende a pontos de vista vinculados a interesses, mas o fato é que, na égide da Constituição Federal de 1988, esse modelo de descentralização fortaleceu as políticas públicas, entendendo-se aí o necessário financiamento para sua execução, embora não seja um aspecto suficiente para sua excelência (LUCENA, 2013), pois a falta de estrutura e de corpo técnico nos municípios, bem como as práticas de gestão incipientes, apresentam-se como grandes entraves para a qualidade da gestão das políticas públicas.

Alguns atores, como Arretche (2012), apontam que a descentralização se fez acompanhada de uma maior regulação por parte do poder central, o que se materializou em um papel não só normativo, mas de apoio técnico e de suplementação financeira, visando minorar desequilíbrios regionais (MARTINS,2011), mas também servindo ao jogo de poder federal, que reflete as lutas subnacionais e eleitorais.

O modelo instituído na Constituição Federal de 1988 é denominado federalismo de cooperação, pela existência de competências comuns e concorrentes entre os entes políticos, com um diferencial da autonomia dos municípios no modelo federativo brasileiro. Entretanto, segundo Abrúcio (2010), esse processo se converte na prática em um federalismo compartimentalizado, com poucos exemplos de cooperação, demandando, para o sucesso, uma maior articulação, com a coordenação da esfera federal (SILVA; 2010) e a existência de mecanismos globais de monitoramento e avaliação (COHEN, FRANCO; 2007) e ainda, sistemas de informação que permitam a articulação com os atores locais, com transparência e governança (OLIVEIRA; FALEIROS; DINIZ, 2015), o que suscita as discussões atuais na construção de um Sistema Nacional de Educação, como reforçado por Braga (2013, p. 172):

A experiência de articulação ainda demanda exercício, tendo como pioneira a criação do Sistema Único de Saúde (SUS), por força da Reforma Sanitária na década de 80/90, bem como a recente criação do Sistema Único de Assistência Social (SUAS), em 2011, e a discussão sobre a criação de um sistema nacional de educação, como aponta Cury (2010), entre outras apresentadas no contexto da Conferência Nacional de Educação em 2010. Mas, ainda assim, os cidadãos sofrem pelos problemas de falta de coordenação dos entes na execução de competências concorrentes e comuns definidas no corpo do texto constitucional.

A política educacional, nesse contexto, por força do art. 211 da Constituição Federal de $1988^{5}$ e dos artigos 74 e 75 da Lei n 9.394, de 20 de dezembro de 1996 (Lei de Diretrizes e Bases da Educação Nacional), apresentam essa repartição de competências, com as ações de cooperação entre os entes políticos e supletiva à competência da União, em especial o emblemático caso da educação básica, que tem a execução ao encargo das esferas estadual e municipal, com ações executivas no âmbito da União, como no caso da Rede de Educação Profissional e Tecnológica, o Colégio Pedro II, colégios de aplicação e os colégios militares.

Um difícil jogo federativo, no qual a accountability encontra dificuldade de se atribuir responsabilização política delimitada ou de punir agentes públicos e entes políticos e ainda, a desigualdade na adesão às políticas nacionais pelas diversas regiões, seja pelas carências técnicas, seja pelos acordos, poderes e conveniências políticas no cenário nacional.

5 Art. 211. A União, os Estados, o Distrito Federal e os Municípios organizarão em regime de colaboração seus sistemas de ensino.(...) § $1^{0}$ A União (...) exercerá, em matéria educacional, função redistributiva e supletiva, de forma a garantir equalização de oportunidades educacionais e padrão mínimo de qualidade do ensino mediante assistência técnica e financeira aos Estados, ao Distrito Federal e aos Municípios 


\section{O Fundeb e o financiamento da Educação Básica}

O financiamento da educação pública brasileira tem como sua principal base a arrecadação de impostos associada à vinculação de parte das receitas à manutenção e ao desenvolvimento do ensino, conforme preceitua o artigo 212 da Constituição. Porém, podem ser citadas outras fontes como as contribuições sociais (com destaque para a contribuição do salário-educação), as transferências voluntárias aos entes subnacionais e as linhas de crédito de financiamento interno e externo. É preciso apontar que, em muitos casos, as legislações que coordenam essas várias fontes operam em lógicas e linguagens diferentes, o que pode gerar confusão de implementação para os gestores e maior dificuldade no seu controle (GOMES, 2013).

Outra nota característica do financiamento da educação básica é seu já mencionado caráter cooperativo. Na concretização dessa cooperação, além da suplementação da União por meio de seus diversos programas de execução descentralizada na área da educação, como os de alimentação e transporte escolar, pode-se citar como um dos mais importantes instrumentos de vinculação e distribuição de recursos a criação do Fundef em 1996 e sua substituição, em 2006, pelo Fundeb.

Para entender a construção e o funcionamento do Fundeb é necessário acessar a leitura da redação original do artigo $60^{6}$ do Ato das Disposições Constitucionais Transitórias, além de sua redação modificada, que deu origem ao Fundef.

Extrai-se da leitura sistemática dos dispositivos citados que a União deveria destinar 9\% e os Estados, Distrito Federal e Municípios 12,5\% de sua receita líquida de impostos para investir na expansão do ensino fundamental e na erradicação do analfabetismo nos dez anos seguinte à promulgação do Texto Maior (ou seja, até o fim de 1998). Esse dispositivo deixa clara a escolha política de, no campo educacional, priorizar, naquele momento, o combate ao analfabetismo e a universalização do ensino fundamental.

No entanto, segundo autores da área da educação, não se verificou o efetivo cumprimento desse mandamento constitucional. Nesse sentido, José Marcelino de Rezende Pinto(2000) explica que: "enquanto, de uma forma geral, os estados e municípios (com exceção dos paulistas) cumpriram essa determinação, o mesmo não acontecia com o governo federal”.

Segundo o estudioso, a falta de efetividade da ordem constitucional e "as grandes disparidades no padrão de qualidade do ensino oferecido, existentes entre regiões e entre redes de ensino, levaram o governo federal a propor uma alteração na redação do art. 60 do ADCT" (PINTO, 2000, p.100), a qual levou à criação do Fundef.

Quanto a essa desigualdade entre as diferentes redes de ensino, é preciso considerar que, historicamente, essa homogeneidade não se fez presente na oferta do serviço educacional brasileiro. Romualdo Portela de Oliveira e Sandra Zákia Sousa (2010, p. 13) explicam que:

Ao analisar-se a educação no Brasil percebe-se a desigualdade inter e intrarregional, decorrente da assimetria entre as condições econômicas dos entes federados e a distribuição de competências previstas constitucionalmente, que indica o que cabe a cada um realizar no tocante ao provimento da educação para a população, resultando em diferentes condições de oferta.

Os autores referidos explicam que a origem dessa desigualdade remonta ao momento em que a educação passou a ser responsabilidade dos Estados (Ato Adicional de 1834 e é reforçado pela Constituição de 1891) e o serviço educacional oferecido por cada um deles diferencia-se significativamente, surgindo dois modelos paradigmáticos no trato da educação, descritos pelos autores da seguinte forma:

0 que se manifesta nos estados do Sul e Sudeste que assumiram a responsabilidade pelo atendimento educacional e construíram, ao longo do Século XX, sistemas próprios de ensino, recorrendo subsidiariamente aos municípios;

0 dos estados do Norte e Nordeste em que estes se omitiram de construir um sistema de ensino de massas e tal responsabilidade foi precariamente assumida pelos municípios (OLIVEIRA; SOUSA, 2010).

6 Art. 60. Nos dez primeiros anos da promulgação da Constituição, o poder público desenvolverá esforços, com a mobilização de todos os setores organizados da sociedade e com a aplicação de, pelo menos, cinquenta por cento dos recursos a que se refere 0 art. 212 da Constituição, para eliminar 0 analfabetismo e universalizar 0 ensino fundamental.

Parágrafo único. Em igual prazo, as universidades públicas descentralizarão suas atividades, de modo a estender suas unidades de ensino superior às cidades de maior densidade populacional. 
Esta diferença deveu-se à estrutura tributária vigente à época, que permitiu aos Estados mais ricos assumirem diretamente a responsabilidade pela oferta do serviço educacional, enquanto os estados mais pobres acabaram por relegá-la a seus municípios (também pobres) (OLIVEIRA; SOUSA, 2010).

O artigo 60 do ADCT, em sua redação original, embora tenha fomentado o desenvolvimento da educação no país, dando prioridade à erradicação do analfabetismo, a partir da vinculação de verbas com esse objetivo, não demonstrou preocupação em mitigar as desigualdades regionais no âmbito educacional.

Em meio a esse contexto, a Emenda Constitucional n 14 de 1996 altera a redação deste artigo e cria o Fundo de Manutenção e Desenvolvimento do Ensino Fundamental e de Valorização do Magistério (Fundef), com a proposta de "um critério mais razoável para a divisão dos recursos vinculados, de modo a que, minimamente, se articulassem aportes financeiros às respectivas responsabilidades" (OLIVEIRA; SOUSA, 2010, p. 17).

É preciso enfatizar que o Fundef não criou novas fontes de receita para a área da educação, apenas determinou e instrumentalizou uma subvinculação dos recursos já existentes para o ensino fundamental. A composição do fundo se deu pela subvinculação de 60\% dos recursos de aplicação obrigatória por Estados e municípios (art. 212 CF/88) à manutenção e ao desenvolvimento do ensino fundamental, com o objetivo de assegurar a universalização de seu atendimento e a remuneração digna do magistério. Quanto à União, esta era obrigada a aplicar 30\% dos recursos para a erradicação do analfabetismo, para a manutenção e desenvolvimento do ensino fundamental e para a complementação do Fundef.

O fundo direcionava-se apenas ao ensino fundamental, criando padrões diferentes para o ensino básico e induzindo os alunos a frequentarem escolas de redes de ensino diferentes. Além disso, deve-se observar que o Fundef dirigia-se apenas à rede regular de ensino fundamental, tendo impacto negativo no atendimento educacional de jovens e adultos (EJA), na educação infantil e na rede especial de ensino (PINTO, 2007).

Foi muito questionada a maior liberdade dada à União na aplicação dos recursos vinculados, o que implicaria em menor responsabilidade da União em comparação aos estados e municípios. O fato de a subvinculação ter sido estipulada pelo prazo pré-determinado de 10 anos, contados da publicação da Emenda Constitucional $n^{\circ} 14$ de 1996, trouxe à baila questões relacionadas à dificuldade de planejamento e à insegurança política e administrativa para os gestores subnacionais.

Nesse cenário, as fortes críticas direcionadas ao Fundef quanto à primazia dada ao ensino fundamental em relação às outras etapas do ensino básico, o grande impacto indutor que o Fundef apresentou no processo de municipalização e a proximidade do fim do prazo estabelecido pela Emenda Constitucional no 14 de 1996 levaram à edição da Emenda Constitucional n 53 de 2006, que alterou novamente o artigo 60 do ADCT, criando o Fundeb.

O Fundo de Manutenção e Desenvolvimento da Educação Básica e Valorização do Magistério é regulamentado pela Lei $n^{\circ} 11494 / 2007$ e pelo Decreto 6.253/2007 e seu prazo de vigência previsto é até o $14^{\circ}$ ano após a publicação da emenda, ou seja, até 31 de dezembro de 2019.

O Fundeb manteve quase integralmente a lógica de funcionamento do Fundef. Comporta esclarecer que se tratam, na realidade, de 27 fundos de natureza contábil, no âmbito de cada Estado e do Distrito Federal, compostos pelas receitas abaixo discriminadas:

\section{Quadro 2: Tributos componentes do Fundeb}

\begin{tabular}{|c|c|}
\hline Estados e Distrito Federal & $\begin{array}{r}20 \text { \% sobre: Quota estadual do ICMS; Quota estadual do IPVA; Imposto sobre Transmissão Causa } \\
\text { Mortis; Fundo de Participação dos Estados; Quota estadual IPI-Exportação. }\end{array}$ \\
\hline Municípios & $\begin{array}{r}20 \% \text { sobre: Quota municipal do ICMS; Quota municipal do IPVA; Quota municipal do ITR; Fundo de } \\
\text { Participação dos Municípios. }\end{array}$ \\
\hline União & $\begin{array}{r}\text { Complementa o valor do Fundeb com 9,5 bilhões nos } 3 \text { primeiros anos, após os quais o valor da } \\
\text { complementação passa a ser, no mínimo, 10\% da contribuição dos estados e municípios. } \\
\text { Pode gastar até 10\% do valor de complementação para auxílio de projetos. }\end{array}$ \\
\hline
\end{tabular}

Fonte: Lucena (2013) 
As receitas são repassadas aos fundos, de forma automática, nos mesmos prazos das fontes que a compõem, por meio de depósito em conta específica do Banco do Brasil. A distribuição de seus recursos se dá na proporção da matrícula dos alunos na educação básica presencial pública de cada rede de ensino e também nas escolas conveniadas sem fins lucrativos (creches e pré-escolas até o ano de 2016 e educação especial exclusiva), com base no Censo do MEC do ano anterior. Esse modo de distribuir os recursos, segundo Cesar Callegari (2013, p. 244), "sintetiza a valia maior do Fundeb: (...) tornar o aluno um fator de receita, deixando de ser apenas um fator de despesa".

Deve-se atentar para o fato de que os fatores de ponderação do custo-aluno são diferentes em cada etapa e modalidade de ensino, o que gera críticas por parte de educadores que questionam os critérios utilizados para seu estabelecimento. Por outro lado, essa diferença dos fatores pode ser vista como instrumento para direcionar os esforços dos gestores para determinadas etapas escolares, auxiliando o fluxo pelas etapas de ensino.

Quanto à utilização dos recursos do fundo, além da necessária observação das regras dos artigos 70 e 71 da LDB, os quais estipulam o que é ou não despesa de manutenção e desenvolvimento do ensino, manteve-se a determinação já existente no Fundef de que $60 \%$ dos recursos do fundo sejam destinados ao pagamento dos professores em efetivo exercício no magistério. Como novidade do Fundeb, criou-se a possibilidade de que $10 \%$ do valor da complementação da União seja direcionada a projetos para melhoria da qualidade da educação básica em regime de colaboração entre as unidades federativas.

De forma resumida, as principais diferenças entre o Fundef e o Fundeb foram organizadas no quadro a seguir:

\section{Quadro 3: Comparação entre Fundeb e Fundef}

\begin{tabular}{|c|c|c|}
\hline Característica & FUNDEF & FUNDEB \\
\hline Composição dos recursos & ICMS+FPE+FPM+IPI-Exp. + LC 87/96 & $\begin{array}{c}\text { ICMS+FPE+FPM+IPI-Exp. + LC 87/96 + IPVA+ } \\
\text { ITR +ITCD }\end{array}$ \\
\hline Alíquota & $15 \%$ & $20 \%$ \\
\hline Complemento da União & $\begin{array}{c}\text { Segundo a EC 14: garantir mínimo igual à média } \\
\text { (0 que equivaleria a cerca de } R \$ 5 \text { bilhões/ano) } \\
\text { Real: } R \$ 314 \text { milhões em } 2006\end{array}$ & $\begin{array}{l}\mathrm{R} \$ \text { 9,5 bi em } 3 \text { anos (depois: mínimo 10\% da } \\
\text { contribuiçãao de estados e municípios) }\end{array}$ \\
\hline $\begin{array}{l}\text { Critério de repartição dos recursos } \\
\text { entre estados e municípios }\end{array}$ & Alunos no Ensino Fundamental Regular público & $\begin{array}{l}\text { Alunos da educação básica presencial: pública } \\
\text { + conveniadas [creche e pré (por } 4 \text { anos) e ed. } \\
\text { Especial exclusiva] }\end{array}$ \\
\hline $\begin{array}{l}\text { Recursos da complementação da } \\
\text { União para projetos }\end{array}$ & Não existe & $\begin{array}{c}\text { Até } 10 \% \text { (para estados que recebam a } \\
\text { complementação) }\end{array}$ \\
\hline Profissionais do magistério & $60 \%$ & $60 \%$ \\
\hline Piso salarial nacional & Omite & $\begin{array}{c}\text { Lei } 11738 \text { de } 2008 \text { (estabelece } R \$ 950,00 \\
\text { para } 40 \text { h semanais; hoje esse valor é de } R \$ \\
1.917,78)\end{array}$ \\
\hline Custo-aluno qualidade & $\begin{array}{l}\text { A ser implantado a partir de } 31 / 12 / 2001 \text { (Obs: } \\
\text { nunca foi) }\end{array}$ & $\begin{array}{l}\text { Previsto no mais recente Plano Nacional de } \\
\text { educação (meta 20.2), com prazo de } 2 \text { anos } \\
\text { para ser implantado. }\end{array}$ \\
\hline
\end{tabular}

Fonte: Tabela retirada originalmente de PINTO (2007) e atualizada pelos autores.

É interessante observar que, apesar do Fundeb apresentar alíquota e número de imposto subvinculados maiores do que o Fundef, o número de alunos a serem atendidos com essas verbas também aumentou substancialmente. Assim, a mudança do Fundef para o Fundeb não necessariamente representou um aumento 
de verbas capaz de melhorar a qualidade do ensino oferecido. Segundo Pinto (2007), a alteração no valor oferecido por aluno foi muito pequena.

Por outro lado, a determinação para que a União complementasse o valor repassado pelos "Fundefs" (e, posteriormente, pelos Fundebs) aos Municípios, com base em um valor mínimo comum por aluno, foi extremamente festejada pela comunidade educacional. Não obstante isto, as expectativas não se tornaram realidade e a criação do fundo não promoveu uma mudança substancial nos valores gastos por aluno/ano, devido aos patamares mínimos de gastos serem muitos baixos, reduzindo a complementação da União a valores insuficientes para o cumprimento da função preconizada pela legislação.

Há, na realidade, muitas críticas quanto ao modo como a complementação da União se dá, mas para entendê-las é preciso fazer uma análise que abranja outros dois conceitos: o valor aluno/ano mínimo nacional e o padrão mínimo de qualidade.

Segundo o artigo 60, $V$ do ADCT :

A União complementará os recursos dos Fundos a que se refere o inciso II do caput deste artigo sempre que, no Distrito Federal e em cada Estado, o valor por aluno não alcançar o mínimo definido nacionalmente, fixado em observância ao disposto no inciso VII do caput deste artigo, vedada a utilização dos recursos a que se refere $0 § 5^{\circ}$ do art. 212 da Constituição Federal.

O mencionado inciso VII do artigo 60 do ADCT determinava que o valor total da complementação da União fosse de 2 bilhões de reais no primeiro ano de vigência dos fundos (2007), 3 bilhões no segundo (2008), 4,5 bilhões no terceiro ano (2009) e, no mínimo, 10\% dos despendido por estados e municípios a partir do quarto ano.

Segundo Callegari (2013), o valor aluno/ano mínimo nacional é um "valor de referência relativo às séries iniciais do Ensino Fundamental urbano e não poderá ser inferior àquele fixado nacionalmente no último ano do Fundef". Sua importância é enorme, vez que se relaciona intrinsecamente com a complementação da União, bem como com o reajuste do piso nacional do magistério.

Houve enorme polêmica quanto ao modo de fixação dos valores mínimo nacionais. À época do Fundef, estudiosos como Martins (2004, p. 184) afirmaram que o artigo $6^{\circ}$, $\S 1^{\circ}$ da Lei $9.424 / 96$ indicava a intenção do legislador de que:

(...) 0 parâmetro para determinar a ação complementar da União fosse a média nacional de capacidade de investimento por aluno do ensino fundamental, com os recursos separados para o FUNDEF. Os recursos federais seriam encaminhados aos Estados cujo valor aluno/ano não alcançasse essa média nacional, que seria o valor mínimo anual nacional, por aluno.

Ou seja, o valor da complementação da União dependeria do valor mínimo nacional, o qual corresponderia a uma média nacional da capacidade de investimento por aluno com os recursos do Fundo.

Outros pesquisadores relacionaram a complementação da União com o padrão mínimo de qualidade previsto no parágrafo primeiro do artigo 211 da Constituição Federal'. Entretanto, não houve a estipulação desse padrão mínimo de qualidade, e a interpretação do Poder Executivo quanto à sua complementação diferiu da apresentada acima.

Na prática, é o valor mínimo destinado para a complementação da União que determina o valor aluno ano/ mínimo nacional. Para melhor explicar a relação entre esses valores, colaciona-se a baixo as etapas de sua definição, segundo a nota explicativa anexada à Lei nº 11.494 de 2007:

1.Ordenação decrescente dos valores anuais por aluno obtidos nos Fundos de cada Estado e do Distrito Federal. 2. Complementação do último Fundo até que seu valor anual por aluno se iguale ao valor anual por aluno do Fundo imediatamente superior. 3. Uma vez equalizados os valores anuais por aluno dos Fundos, conforme operação2, a complementação da União será distribuída a esses dois Fundos até que seu valor anual por aluno se iguale ao valor anual por aluno do Fundo imediatamente superior. 4. As operações $2 \mathrm{e} 3$ são repetidas tantas vezes quantas forem necessárias, até que a complementação da União tenha sido integralmente distribuída, de forma que o valor anual mínimo por aluno resulte definido nacionalmente em função dessa complementação (CALLEGARI, 2013, p. 240)

7 Art. 211. A União, os Estados, o Distrito Federal e os Municípios organizarão em regime de colaboração seus sistemas de ensino.

$\S 1^{\circ}$ A União organizará o sistema federal de ensino e o dos Territórios, financiará as instituições de ensino públicas federais e exercerá, em matéria educacional, função redistributiva e supletiva, de forma a garantir equalização de oportunidades educacionais e padrão mínimo de qualidade do ensino mediante assistência técnica e financeira aos Estados, ao Distrito Federal e aos Municípios (Grifo nosso). 
Assim, o que se observa é a estipulação de valores anuais bem inferiores ao valor médio nacional. Esta situação é muito criticada pelos acadêmicos e profissionais da área que apontam que a maneira com que a União complementa os valores dos Fundos não cumpre integralmente o papel redistributivo e equilibrador que era esperado e necessário.

O novo PNE, com suas referências expressas (metas 20.6, 20.7 e 20.10) a (i) determinação de um custo aluno qualidade ${ }^{8}$, (ii) sua implementação como parâmetro para o financiamento da educação básica e (iii) complementação da União para que Estados e Municípios atinjam esse padrão, é uma resposta a essas críticas.

A despeito das críticas, o modelo introduzido pelo Fundef e ampliado pelo Fundeb consolidou-se nesses quase 20 anos como um modelo hegemônico de financiamento da educação, presente em todos os municípios brasileiros, constituindo, sem dúvida, a principal fonte de financiamento da educação básica nos municípios brasileiros.

Ressalta-se, contudo, que um desenho pensado pela lógica do financiamento e sua equidade necessita atender também requisitos de accountability, composto por atores e inovações institucionais, como se verá a seguir.

\section{Atores do sistema de accountabilty do Fundeb}

Conforme dito, o Fundeb foi pensado de forma prioritária pelo prisma do equilíbrio da alocação dos recursos, com um desenho próprio de accountability, o qual será descrito, visando a análise, tendo como foco a gestão municipal do Fundo.

No âmbito municipal, tem-se como ator principal, em termos executivos, a Secretaria Municipal de Educação ou órgão equivalente, responsável pela gestão do fundo, em especial da sua conta única e específica (Art.17 da Lei $n^{\circ}$ 11.494/2007 e Art. 8 do Decreto $n^{\circ}$ 6.253/2007) e tem um sistema de accountability com três atores: (i) 0 controle interno municipal, previsto no Art. 74 da Constituição Federal e no Art. 26 da Lei n 11.494/2007, que pela sua insipiência, temos um cenário de órgãos ainda pouco estruturados e por vezes, nem implementados (CONACl, 2014); (ii) a Câmara dos Vereadores, órgão do legislativo municipal, que tem como funções constitucionais a fiscalização do Poder Executivo, por força dos artigos 30, 70 e 71 da Constituição Federal e uma novidade institucional, herdada do Fundef, (iii) o Conselho de Acompanhamento e Controle Social-CACS do Fundeb.

Estudos de Braga (2015), a partir de dados de fiscalização da Controladoria-Geral da União (CGU), indicam fragilidades na atuação desses conselhos do Fundeb, em especial quanto a capacitação dos conselheiros, a falta de apoio para o funcionamento, um baixo acompanhamento da gestão e ainda, a restrição no acesso aos recursos geridos, com a construção de um modelo de controle social preponderantemente técnico, na centralidade da emissão de um parecer, em detrimento do sofrível aspecto político-participativo.

Ainda na esfera local, conforme prescrito no Art. 27 da Lei do Fundeb, a prestação de contas regular do Fundo e a fiscalização cabe aos Tribunais de Contas Estaduais ${ }^{9}$, com a atuação do Ministério Público Estadual (Art. 29 da Lei) no âmbito de sua competência, admitida a atuação do Ministério Público Federal por conta de entendimento do Supremo Tribunal Federal e pelo Art. 29, §2 da Lei n 11.494/2007.

Nos municípios que recebem a complementação da União para atingir o valor mínimo por aluno, o entendimento dominante é que eles são objeto de fiscalização pelo Tribunal de Contas da União (TCU) e da CGU, tema controverso pela ambiguidade da Lei, e que foi objeto de regulamentação infra legal pelo TCU dois anos após a promulgação da Lei do Fundeb, pela publicação da Instrução Normativa nº 60 /2009, que indica no

8 Conforme Lei do PNE (Lei $\mathrm{n}^{0}$ 13.005/2014), o Custo Aluno-Qualidade (CAQ) é Custo Aluno Qualidade - CAQ é um parâmetro para o financiamento da educação de todas etapas e modalidades da educação básica, a partir do cálculo e do acompanhamento regular dos indicadores de gastos educacionais com investimentos em qualificação e remuneração do pessoal docente e dos demais profissionais da educação pública, em aquisição, manutenção, construção e conservação de instalações e equipamentos necessários ao ensino e em aquisição de material didático-escolar, alimentação e transporte escolar. É uma inversão da lógica de mínimos possíveis para o necessário para suportar financeiramente uma Educação de qualidade.

9 Há, no Brasil, dois Tribunais de Contas Municipais: o Tribunal de Contas do Município do Rio de Janeiro e o Tribunal de Contas do Município de São Paulo, tendo em vista que a abertura de novos tribunais de contas municipais foi vedada pela Constituição Federal de 1988. Quanto aos Tribunais de Contas dos Municípios, órgãos estaduais responsáveis pelo julgamento das contas dos municípios, e que existem apenas nos estados da Bahia, Ceará, Pará e Goiás. 
seu Art. 10 que o TCU atuará em órgãos municipais que recebem a complementação da União, podendo aplicar multas e, no caso de dano ao erário, determinar a instauração do procedimento de Tomada de Contas Especiais que seguirá para o Tribunal de Contas Estadual, objeto da prestação de contas. Este entendimento estende a competência a CGU por força do Art. 70 e 74 da Constituição Federal.

Desse modo, nos municípios que recebem a complementação da União, conforme o Quadro IV, existe uma fiscalização concorrente com um acréscimo de atores, ampliando quantitativamente o sistema de accountability do Fundeb.

Quadro 4: Evolução da complementação de recursos da União ao Fundeb.

\begin{tabular}{|c|c|c|}
\hline Ano & Complementação da União (Bilhões de Reais) & \multicolumn{1}{|c|}{ Estados } \\
\hline 2007 & 2,012 & AL, BA, CE, MA, PA, PB, PE, PI \\
\hline 2008 & 3,174 & AL, AM, BA, CE, MA, PA, PB, PE, PI \\
\hline 2009 & 5,071 & AL, AM, BA, CE, MA, PA, PB, PE, PI \\
\hline 2010 & 5,831 & AL, AM, BA, CE, MA, PA, PB, PE, PI \\
\hline 2011 & 9,328 & AL, AM, BA, CE, MA, PA, PB, PE, PI \\
\hline 2012 & 10,372 & AL, AM, BA, CE, MA, PA, PB, PE, PI \\
\hline 2013 & 9,180 & AL, AM, BA, CE, MA, PA, PB, PE, PI \\
\hline
\end{tabular}

Fonte: Tesouro Nacional/FNDE

Verifica-se assim uma múltipla e complexa estrutura de accountability da gestão municipal do Fundeb, com o controle interno, externo, social e o Ministério Público, interações interfederativas como o Fundeb e que tem uma visível centralidade na ação do controle social, pela via dos CACS-FUNDEB.

Apesar dessa generosa rede de agências, as aparições do Fundeb nos periódicos revela problemas relevantes, sintetizados por Braga (2015) e pela Avaliação da Execução do Programa realizada pela CGU (BRASIL, 2013), indicando como problemas na gestão desvios de finalidade, falta de comprovação das despesas, irregularidades nas licitações e contratos, não observância do mínimo com a remuneração dos professores e movimentações fora da conta específica, o famoso "saque na boca do caixa", sendo que esta última situação mobilizou o Governo Federal para, por meio do Decreto nº 7.507 de 27/06/2011, instituir medidas de promoção da transparência dos recursos do Fundeb e restrições a movimentações que não se deem de forma eletrônica, rastreável, fortalecendo a gestão do Fundo.

\section{Análise do sistema de accountability do Fundeb}

$\mathrm{Na}$ análise do desenho de accountability do Fundeb, a luz da tipologia construída com base nos conceitos dos autores escolhidos, é possível se identificar virtudes e fraquezas dessa estrutura de gestão do fundo, para de forma propositiva, estabelecer novas práticas e novos resultados.

(i) A primeira questão é que o desenho da pretensa colaboração federativa possa favorecer, pela falta de segregações mais explícitas, situações, no mínimo, curiosas, pois:

(...) no federalismo de cooperação, de responsabilidades comuns entre os entes, na hora dos sucessos uma maximização da paternidade, que pode se transformar em evasivas no momento do escândalo. Da mesma forma, a participação social pode ser ver encilhada pela supremacia da democracia representativa, em um processo que sujeita a escolha a oferta de candidatos disponíveis. 0 poder, em suas diversas manifestações, pela sua natureza, vai tentar encontrar formas de burlar os mecanismos de sua mitigação em relação aos anseios coletivos. É a famosa briga do rochedo contra o mar...(BRAGA, 2015 a, p.1) 
Assim, com múltiplos atores, de agências a instâncias de democracia participativa e representativa, o risco da difusão de responsabilidades é uma realidade no federalismo, e que se exemplifica no Fundeb, fruto de um desenho pensado na execução e que aposta no accountabilitypelo controle mútuo entre essas esferas, mas que não contam com uma coordenação estratégica desse processo, em lutas de autonomias e competências, nos quais os resultados jazem, por vezes, esquecidos.

(ii) Na aplicação mais estrita da tipologia de avaliação da accountability, utilizando-se como lócus de análise a Secretaria Municipal de Educação, tem-se que a transparência e a disponibilização de informações é fortalecida por vários diplomas legais, como a alteração da Lei de Responsabilidade Fiscal pela Lei Complementar $n^{\circ}$ 131/2009 (Lei Capiberibe), o já citado Decreto n 7507/2011, a Lei de Acesso a Informação(Lei n 12.527/2011) e o Art. 30 da Constituição Federal de 1988, reforçados pela necessidade de disponibilização dos dados aos CACS do Fundeb, por força do Art. 25 da Lei no 11.494/2007, que rege o fundo.

A robustez das normas de transparência - um processo em amadurecimento não só no Fundeb, mas no país como um todo - é compensada por uma baixa necessidade legal de exposição da motivação dos atos desenvolvidos e mais, pela carência de agregados avaliativos que permitam a mensuram os macro resultados do Fundeb no âmbito estratégico, entendendo-se aí ao nível nacional.

(iii) A Lei do Fundeb se limita a estabelecer que os gastos do fundo dar-se-ão na manutenção e desenvolvimento da Educação Básica, elencando um rol de despesas elegíveis, oriundas do Art. 70 e 71 da LDB (Lei $n^{\circ}$ 9.394/1996), o que dificulta uma responsabilização mais estratégica dos administradores municipais, ainda que as recentes discussões da Lei de Responsabilidade Educacional ${ }^{10}$ apresentem essa pauta da qualidade em um plano mais factível, assunto que merece um debate mais aprofundado, pelas peculiaridades do uso de indicadores e responsabilização, quando se fala de políticas sociais.

(iv) Em relação a uma estrutura que favoreça a conformidade e os resultados, a carência de uma cultura de controles internos e de gestão de riscos, uma baixa adesão no plano estatal brasileiro às diretrizes do COSO-Co mmitteeofSponsoringOrganizations of the Treadway Commission, como percebido na carência legislativa e como exemplificado no Acórdão n 821/2014-TCU-Plenário, produz um cenário que contamina a gestão municipal, carente de corpo técnico e de capacitação, o que por si só já fragiliza essa dimensão controle no âmbito da gestão do Fundeb, em uma temática profunda que por si só demandaria um estudo autônomo.

(v) No que tange à sanção, no âmbito do sistema de accountability do Fundeb, temos um desenho de múltiplos atores com a capacidade punitiva e interventiva, com competências concorrentes e não em uma linha de supervisão, com a possibilidade de se gerar conflitos de competência e até interpretações dispares, como no caso do uso de recursos do Fundeb para o pagamento de aposentadorias ${ }^{11}$ e ainda, a geração de desigualdades desse caráter sancionatório, pelas diferentes atuações dos Tribunais de Contas Estaduais (DAVIES, 2001; TREVISAN, 2003) e pela inserção de players robustos, como a CGU e o TCU, em determinados municípios, o que traz, por vezes, o assunto para a pauta nacional.

A concorrência entre esferas fiscalizatórias pode gerar a eficiência, mas pode ser fonte de conflitos, lacunas, inseguranças e concentrações de atuação e no que se refere ao foco da atuação da instituição, essa difusão gera possibilidades de protelações e de fugas, por romper a ideia linear de um "fiscalizador natural12" e de níveis de supervisão.

10 Conforme Plano Nacional de Educação -20.11) aprovar, no prazo de 1 (um) ano, Lei de Responsabilidade Educacional, assegurando padrão de qualidade na educação básica, em cada sistema e rede de ensino, aferida pelo processo de metas de qualidade aferidas por institutos oficiais de avaliação educacionais.

11 Vide caso concreto em http://g1.globo.com/rn/rio-grande-do-norte/noticia/2013/09/mp-investiga-suposta-improbidade-no-uso-de-verbas-do-fundebno-rn.html

12 A similitude do conceito jurídico do Juiz natural, que estabelece que devem haver regras objetivas de competênciajurisdicional, garantindo a independência e a imparcialidadedo órgão julgador. 
(vi) Já no campo da discussão do sistema de accountability propriamente dito, nos aspectos horizontais, do controle mútuo, as perdas se dão pelo desequilíbrio entre as agências, dispersas em diversos níveis federativos, o que pode gerar conflitos e não equilíbrio. Temos agências de fiscalização e sancionamento federais, municipais e estaduais, problema que se repete em outros programas descentralizados da Educação, dado que a lógica destes programas no federalismo é focada na distribuição de recursos, com uma baixa relevância dessa dimensão de accountability.

No que tange às interações verticais, pela linha eleitoral, esta é contemplada na responsabilização do gestor se dar no nível municipal, com recursos segregados na Educação e vultosos proporcionalmente nos municípios no que afeta ao Fundeb, o que facilita a percepção de sua aplicação. Por exemplo, os estudos de Ferraz \& Finam (2007) demonstram que a liberação dos resultados de auditoria da CGU tiveram um impacto significativo sobre o desempenho dos candidatos municipais, e que esses efeitos foram mais pronunciados nos municípios onde existia rádio local presente para divulgar as informações, raciocínio que nos permite inferir que a interação da população, mediada pela dimensão horizontal dos órgãos de controle, permite a sanção e a responsabilização dos gestores municipais de políticas sociais, independente da origem dos recursos, importando a "gestão percebida", o que se aplica ao Fundeb.

Na verticalização, na linha do controle social, os CACS-Fundeb tem um desenho paritário e técnico-burocrático que não possibilita, na prática, a mediação cotidiana dos sindicatos e movimentos sociais (BRAGA, 2015) com a gestão local, impedindo a interação que traga resultados, não permitindo a interação com a dimensão horizontal, pela falta de normativos que empoderem esses conselhos junto aos órgãos de controle, como apontado pela CGU na avaliação do Fundeb (BRASIL, 2013).

Face ao exposto, a análise da sinergia entre os atores verticais e horizontais se mostra prejudicada pela falta de coordenação e até de fluxos de trabalhos e de informações, do trato de denúncias, o que impossibilita parcerias mais destacadas. No caso dos conselhos, interações dos diversos conselhos no âmbito regional e nacional, com a interação com os órgãos de controle, propiciaria uma rede de informações e de aprendizado que fortaleceria em muito a sinergia, rompendo essa visão atomizada do Fundeb no que tange a accountability.

De forma sintética, a análise indica que nem sempre a quantidade de atores em um sistema de accountability implica em qualidade desta, exigindo coordenação, fluxos de informação, controles mútuos equilibrados e sinergia local e mais ampla, em um movimento orquestrado que realmente possibilite o controle e a garantia dos atingimentos da política, com a construção de diagnósticos globais e norteadores, o que não se vê no Fundeb, dissociando-se o financiamento da governança da política, de forma fragmentada e que fragiliza a gestão.

Resgatando as reflexões de Braga (2011), tem-se que as discussões reinantes nas movimentações que precedem a votação do Plano Nacional de Educação foram na órbita da questão dos 10\% do Produto Interno Bruto como referência na aplicação de recursos orçamentários para a educação. Entidades sindicais, organizações do terceiro setor, políticos, intelectuais, professores universitários, secretarias de educação, associações de estudantes; enfim, diversos atores se organizam em um coro uníssono na questão do orçamento como elemento central na luta pela garantia de uma educação de qualidade social que permitisse os avanços desejáveis - e necessários - do país, e que para se tornar realidade demanda recursos para custear equipamentos, bons salários e atividades de suporte adequados, nas pautas apresentadas no presente artigo, quando das discussões de equalização e quantidade de recursos que permearam a idealização do modelo Fundeb/Fundef.

Entretanto, como forma de alavancar os avanços nessa política, ideia corroborada pelas experiências de outros países e ainda, pela necessidade de superar o ônus da imensa dívida educacional que arrastamos gerações a fio, em processos iniciados no Brasil colônia, a luta por mais recursos é válida e legítima, considerando-se, tão somente, que lutar apenas pelo aumento da participação no orçamento da Educação separa a discussão do financiamento da reflexão sobre seus mecanismos de accountability, que atuam como instrumentos de garantia da efetiva materialização desses recursos junto às comunidades beneficiadas, possibilitando a conversão dos 
créditos orçamentários em uma educação de qualidade social, na escola adequada, no professor bem pago, no acesso ao material didático, como no fortalecimento de arranjos institucionais, para que se possa exercer o controle sobre os recursos, principalmente de forma democrática.

\section{Conclusão}

Após uma revisão teórica de accountability na construção de uma tipologia de análise, com uma dimensão na instituição gestora e outra no sistema ao qual ela está submetida, o artigo analisou a descentralização da política educacional no contexto do federalismo brasileiro, de cooperação, que carece ainda de um desenho sistêmico que dê conta desses múltiplos atores frente à necessidade de um agir eficaz e eficiente, em especial nas políticas públicas construídas a partir de parcerias intrafederativas, como o é a política pública educacional, exemplificada pelo Fundeb.

O artigo demonstrou as dificuldades de accountability em um sistema federativo, com entes autônomos, no qual os controles mútuos são substituídos por redes desiguais de atores em colaboração, com riscos concorrenciais de conflitos, lacunas e assimetria de informações.

Apresenta-se como oportunidade de melhoria as possibilidades de empoderamento dos conselhos e o incremento da transparência, o que fortalecerá a dimensão vertical possibilitando espraiar esse robustecimento para a dimensão horizontal, pela indução e pela pressão por melhores serviços.

Chama a atenção também a necessidade de se fortalecer, no âmbito institucional, os controles internos das secretarias municipais e as estruturas de controle interno municipal e os tribunais de contas estaduais e municipais, com exemplos alvissareiros como a avaliação realizada em conjunto pelos Tribunais, no Ensino Médio (NARDES, 2014), buscando uma coordenação que possibilite mitigar as ações conflitantes e fortalecer a sinergia entre as agências fiscalizadoras no âmbito educacional, na lógica de camadas, de linhas de defesa que se complementam e que se controlam mutuamente ${ }^{13}$, sem perder de vista autonomia e as desigualdades regionais.

O desenho de accountability do Fundeb necessita ser repensado, casado com a discussão da Lei de Responsabilidade Educacional e do Sistema Nacional de Educação, para que nessa lógica federativa, de recursos e competências, possamos ter recursos efetivos que impeçam a captura de orçamentos vultosos e de finalidade tão relevante para o desenvolvimento do país, que contemplem a ação técnica em um viés horizontal, mas que dê vez e voz a população em suas diversas formas de organização.

\section{Referências}

ABRÚCIO, F. L. Desafios contemporâneos para a reforma da administração pública brasileira. In: PETERS, B. Guy; PIERRE, J. Administração Pública: Coletânea. Brasília: Unesp/ENAP, 2010. p. 537-548.

ARRETCHE, M. T. S. Democracia, federalismo e centralização no Brasil. Rio de Janeiro: Editora FGV; Editora Fiocruz, 2012.

BRAGA, M. V. A. Conselhos do Fundeb: participação e fiscalização no controle social da educação. Curitiba: Appris, 2015.

.A sociedade que desejamos é possível sem accountability?Jus Navigandi. Piauí, 2015 A. Disponível em:< http://jus.com.br/artigos/37976/a-sociedade-que-desejamos-e-possivel-sem-accountabilitys,. Acesso em:13 jun. 2015.

Projetos governamentais descentralizados-O que a gerência de riscos pode contribuir para a qualidade dos serviços prestados nesse modelo? In: Braga, M. V. A. (Coord.). Controle interno: estudos e reflexões-Belo Horizonte: Fórum, 2013.

\section{Conforme IIA (2013)}


Plano Nacional de Educação: queremos 10\% sem 10\%. Revista Jus Navigandi Teresina, ano 16, n. 3023,11out.2011. Disponível em:<http://jus.com.br/artigos/20186>.

BRASIL. Constituição da República Federativa do Brasil. Disponível em:< http://www.presidencia.gov.br/ legislacao/>. Acesso em:13 jun. 2015.

. Lei n ${ }^{\circ}$ 9.424, de 24 de dezembro de 1996. Dispõe sobre o Fundo de Manutenção e Desenvolvimento do Ensino Fundamental e de Valorização do Magistério e dá outras providências. Disponível em: <http://www. presidencia.gov.br/legislacao/>. Acesso em:13 jun. 2015.

. Lei n’. 9.394, de 20 de dezembro de 1996. Estabelece as Diretrizes e Bases da Educação Nacional. Legislação, Brasília. 1996. Disponível em: <http://www.presidencia.gov.br/legislacao/>. Acesso em:13 jun. 2015.

Lei $n^{\circ}$ 11.494, de 20 de junho de 2007. Regulamenta o Fundo de Manutenção e Desenvolvimento da Educação Básica e de Valorização dos Profissionais da Educação (FUNDEB). Disponível em: <http://www. presidencia.gov.br/legislacao/>. Acesso em:13 jun. 2015.

. Decreto $n^{\circ} 6.253$, de 13 de novembro de 2007. Dispõe sobre o Fundo de Manutenção e Desenvolvimento da Educação Básica e de Valorização dos Profissionais da Educação - FUNDEB, regulamenta a Lei no 11.494, de 20 de junho de 2007, e dá outras providências. Disponível em: <http://www.presidencia.gov.br/legislacao/>. Acesso em:13 jun. 2015.

. Controladoria-Geral da União. Relatório de Avaliação da Execução de Programas de Governo n 22 -Complementação da União ao Fundo de Manutenção e Desenvolvimento da Educação Básica e de Valorização dos Profissionais da Educação - FUNDEB. Brasilia, 2013. Disponível em:<http://www.cgu.gov.br>. Acesso em:13 jun. 2015.

CALLEGARI, C. O financiamento da Educação Básica in Todos pela educação (org.). Justiça pela qualidade na educação. Editora Saraiva, 2013, p. 223-265.

CENEVIVA, R. Accountability: novos fatos e novos argumentos: uma revisão da literatura recente. Anais do Encontro de Administração Pública e Governança da Associação Nacional de Pós-Graduação e Pesquisa em Administração. São Paulo, SP, 2006.

COHEN, E.; FRANCO, R. Gestão social: como obter eficiência e impacto nas políticas sociais. Brasília: ENAP, 2007. 292 p.

CONACI - Conselho Nacional de Controle Interno. Panorama do Controle Interno no Brasil/Organizadores: Gustavo Gonçalves Ungaro e Raphael Rodrigues Soré. Brasília: CONACI, 2014.

CURY, C. R. J. Os desafios da construção de um sistema nacional de educação. In: BRASIL, Ministério da Educação. Coletânea de textos da CONAE (Tema Central e colóquios). Brasília: CONAE/MEC, 2010.

DAHL, R. Poliarquia. São Paulo, Edusp, 1997.

DAVIES, N. Tribunais de contas e Educação: quem controla o fiscalizador dos recursos? Brasília: Plano Editora, 2001.

FÉLIX ROSAR, M. F. A municipalização como estratégia de descentralização e desconstrução do sistema brasileiro. In: Oliveira, D. A. (Org.). Gestão democrática da educação: Desafios contemporâneos. 8. ed. Petrópolis: Vozes, 2008. p. 105-140

FERRAZ, C.; FINAN, F. Exposing corrupt politicians: the effect of Brazil's Anti-Corruption Program on Electoral Outcomes. IZA DiscussionPapers, n. 2836, 2007.

GOMES, E. C. S. G. O financiamento da Educação Básica no Brasil, in ABMP, Todos pela educação (org.). Justiça pela qualidade na educação. Editora Saraiva, 2013, p. 266-287.

IIA BRASIL- Instituto de Auditores Internos do Brasil. Declaração de Posicionamento do IIA: as três linhas de defesa no gerenciamento eficaz de riscos e controles. IIA Brasil. São Paulo, 2013. Disponível em: <http://www. iiabrasil.org.br/ >. Acesso em:13 jun. 2015.

KOPPELL, J. G. S. World rule: Accountability, legitimacy, and the design of global governance. Universityof Chicago Press, 2010. 
LUCENA, E. V. Competência material, distribuição orçamentária e seu relacionamento com acesso a Educação Básica. Trabalho de Conclusão de Curso (Graduação em Direito)-Universidade de São Paulo/Faculdade de Direito de Ribeirão Preto, 2013. $133 \mathrm{f}$.

MAINWARING, S. Introduction: Democratic Accountability in Latin America. In: MAINWARING, S.; WELNA, C. Democratic Accountability in Latin America.Oxford, Oxford University Press, 2003.

MARTINS, P. S. Fundeb, federalismo e regime de colaboração. Campinas, SP/Brasília, DF: Autores Associados/ Faculdade de Educação da UnB. 2011

MARTINS, R. C. R.Direito à educação: uma questão de justiça.Editora Malheiros, 2004.

NARDES, J. A. R.; AltouniAn, C. S.; VIEIRA, L. A. G. Governança Pública: o desafio do Brasil. Belo Horizonte: Fórum, 2014.

O'DONNELL, G. Horizontal Accountability: The legal institutionalization of mistrust. In: MAINWARING, S.; WELNA, C. Democratic Accountability in Latin America.Oxford, Oxford University Press, 2003. Accountability Horizontal e NovasPoliarquias. Lua Nova, n 44, São Paulo, 1998.

OECD. Avaliação da OCDE sobre o sistema de integridade da Administração Pública Federal brasileira: Gerenciando riscos por uma administração pública íntegra. Brasília: Organização Para a Cooperação e Desenvolvimento Econômico, 2011. 55 p

OLIVEIRA, L. C. P.; FALEIROS, S. M.; DINIZ, E. H. Information systems in decentralized social policies: an analysis of the federal coordination and management practices.Rev. Adm. Pública,Rio de Janeiro, v. 49,n. 1,p. 23-46, fev. 2015 Disponível em <http://www.scielo.br/>.acesso em 14 jun.2015. http://dx.doi.org/10.1590/003476121675.

OLIVEIRA, R. P.; SOUSA, S. Z. O federalismo e sua relação com a educação no Brasil. In: OLIVEIRA, R. P.; SANTANA, W. (orgs). Educação e Federalismo no Brasil: combater as desigualdades, garantir a diversidade. Brasília: UNESCO, 2010, p.13-37.

PESSANHA, C. F. Accountabilitye Controle Externo no Brasil e na Argentina. In: GOMES, A. C. (Coord.).Direitos e Cidadania: justiça, poder e mídia. Rio de Janeiro, FGV Editora, pp.139-167, 2007.

PINTO, J. M. R. Os recursos para a educação no Brasil no contexto das finanças públicas. Brasília: Editora Plano, 2000.

A política recente de fundos para o financiamento da educação e seus efeitos no pacto federativo. Educação \& Sociedade, Campinas,v. 28, n 100, out. 2007. Disponível em <http://www.scielo.br/scielo. php?pid=S0101-73302007000300012\&script=sci_arttext\&tlng=andothers $>$. Acesso em 17 de julho de 2015.

SCHEDLER, A. Conceptualizing Accountability. In: Schedler, A.; Diamond, L.; Plattner, M. The Self-Restraining State: Power and Accountability in New Democracies. LynneRienner Publisher, 1999. P. 13-27.

SILVA, V. A. Federalismo e articulações de competências no Brasil. In: PETERS, B. G.; PIERRE, J. Administração Pública: Coletânea. Brasília: Unesp/ENAP, 2010. p. 549-570

TREVISAN, A. M. O combate a corrupção nas prefeituras do Brasil. 4 Ed. Cotia-SP: Ateliê Editorial, 2003.

Recebido emagosto de 2016 | Aprovado em outubro de 2016 